INTERDISCIPLINARIA ARCHAEOLOGICA NATURAL SCIENCES IN ARCHAEOLOGY

\title{
The Use of the Wheel in the Production of Pithoi: Preliminary Results and Lessons Learnt from Experimental Sessions
}

\author{
Francesca Porta ${ }^{1 *}$

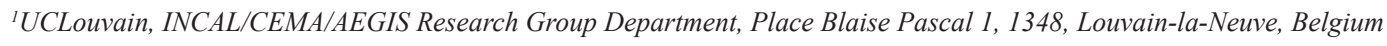

\section{ARTICLE INFO}

Article history:

Received: $1^{\text {st }}$ February 2021

Accepted: $14^{\text {th }}$ August 2021

DOI: http://dx.doi.org/10.24916/iansa.2021.2.4

\section{Key words:}

Pithoi

Experimental Archaeology

Wheel-coiling

Slab-building

Bronze Age

\begin{abstract}
$A B S T R A C T$
Large earthenware storage vessels, known as pithoi, were very widespread in the Mediterranean Basin area, both in domestic and non-domestic contexts, throughout the entire Bronze Age. From a technological point of view, due to their large dimensions, the production of pithoi is very demanding and requires highly skilled and expert artisans. However, despite their large diffusion and their prominent role in resource management, pithoi have received less attention in terms of research in comparison to other types of vessels; technological studies, in particular, stand out for their relative rarity. Indeed, experimental approaches are scant, thus preventing a comprehensive understanding of the manufacturing process of pithoi. This paper presents the preliminary results of two experimental sessions dedicated to the examination of the use of the wheel in the manufacture of these large clay containers. Experimental vessels have been analysed by way of the naked eye and through X-ray analysis.
\end{abstract}

\section{Introduction}

Pithoi, large earthenware storage vessels, were widespread in the Mediterranean area, both in domestic and nondomestic contexts, such as palaces and temples, throughout the Bronze Age (Bevan, 2014; Cyprus: Pilides, 2000; Shuster Keswani, 2009; Crete: Christakis, 2005; Privitera, 2010; Northern Greece: Margomenou and Roumpou, 2011; Anatolia: Kibaroğlu and Thumm-Doğrayan, 2013; Southern Italy and Sicily: Guglielmino, 1999; Schiappelli, 2003; 2015; and Veca, 2015). The importance of pithoi and pitharakia in the Mediterranean is further attested to by their continued production until more recent times, as verified through ethnographic research (Hampe and Winter, 1962; Voyatzoglou, 1974; Blitzer, 1990; Giannopoulou and Demesticha, 2008; Giannopoulou, 2010).

Due to their demanding manufacturing process, pithoi are considered a form of specialised pottery production (Levi, 1999; Giannopoulou, 2010, pp.55-77), and studies on their production technology potentially allow scholars to gather information about productive systems, craft skills, different

*Corresponding author. E-mail: f.porta87@gmail.com levels of specialisation (Shuster Keswani, 2009), and on the organisation of economic systems (Christakis, 2008; Manzanilla and Rothman, 2016). However, technological studies, especially regarding the identification of forming methods, stand out due to their relative rarity (Levi, 1999; Preston Day et. al., 2016; Vankilde, 2016; Keswani, 2017).

This paper presents the initial results from two different experimental sessions dedicated to the investigation of the use of the wheel to produce large clay containers. In the case of pithoi, the wheel could only be linked to wheel-fashioning methods (Roux, 2019, pp.84-92; Jeffra, 2011; Roux and Courty, 1998), as the production of such large-sized vessels by way of wheel throwing is considered impossible.

Independent of the specific techniques utilised, wheel-made vessels present macro traces such as horizontal and parallel rilling striations and grooves on their surfaces. However, as already stated, surface features may be polysemic as they can be the result of different formation processes (Courty and Roux, 1995, p.18). Thus, it is necessary to explore the relationship between formation techniques/methods and macro traces on vessels made by way of experiment.

The experiments presented here were part of a broader study of pithoi-manufacturing technology carried out by the 
author (Porta, 2019) involving Late Bronze Age (hereafter LBA) pithoi found in Italy (Levi, 1999; Guglielmino, 1999; Schiappelli, 2003; 2015), Crete (Christakis, 2005), and Cyprus (Pilides, 2000; Shuster Keswani, 2009). Observation of the surfaces of the vessels combined with the analysis of their X-ray images allowed one to hypothesise that some of these pithoi were made by way of the progressive stacking of clay elements (e.g. coils or slabs), with the use of the wheel (cf. Levi, 1999). The experiments were thus meant as a complementary tool to the research being carried out in order to test the suggested hypothesis (Ascher, 1961; Coles, 1979; Reynolds, 1999; Outram, 2008; O'Sullivan et. al., 2014; Jeffra, 2015), and they were used to gather together a collection of examples of forming traces to be compared with those of the LBA pithoi. At present, experimental collections dedicated to the manufacture of pithoi and large vessels are missing. This biases the possibility to fully understand and interpret technological traces of ancient pithoi, since the formation of the traces and their final aspect can be completely different from the ones of smaller vessels.

Experimental replicas were then analysed using macroscopic inspection and X-rays. Although X-rays and other microscopic analytical techniques ( $c f$. Thér, 2016) are increasingly included in pottery technological studies, they are mainly used directly on archaeological samples and not tested against experimental (Berg, 2008) or ethnographic materials (Porta, 2019). This can lead to misconceptions when identifying traces, so rendering results incomplete and speculative (Livingstone Smith and Viseyrias, 2010). For this reason, a large amount of research has been dedicated to the study of X-ray images of experimental items.

\section{Material and Methods}

The methodology applied in this study consists of a combination of experimental archaeology, macroscopic inspection and X-ray analysis in order to address the identification and investigation of the pithoi-manufacturing process. The experimental framework was organised in two separate and diverse macro sessions, namely Experiments No. 1 and No. 2. All the experimental sessions were filmed and photographed, and all the parameters used (e.g. the amount of clay used, the manufacturing time and the turning speed of the wheel) were recorded. The experimental vessels produced were subsequently analysed by way of macroscopic inspection. Macro traces identified on the external and internal surfaces and the cross-sections were classified according to definitions already established in previous academic research (Courty and Roux, 1995; Roux and Courty, 1998; Jeffra, 2011; Choleva, 2012).

Replicas of the sample in question were further analysed by way of X-ray. Materials were X-rayed at the Radiology Department at the Trebisacce Hospital, Calabria, Italy, by F. Odoguardi using a Carestream CR 975 X-ray machine.
By X-raying the internal structure of the vessels, it was possible to observe the orientation of their inclusions and the orientation and shape of the voids imprinted by the primary forming methods. The ability to understand the internal structure of the vessels largely depends on the contrast between the clay matrix and the inclusions/voids within. The use of a very fine clay matrix, such as modern industrial clay, or an excessive quantity of temper can both obscure the manufacturing traces and preclude the identification of the manufacturing technique (Laneri, 2009, p.49; Berg, 2008, p.1186). For this reason, in Experiment No. 2, a specific amount of temper and X-ray markers, namely, manganese oxide (Desogus et. al., 1995), was added to the industrial clay to better identify technological traces. Moreover, in order to make the X-ray images, usually in shades of grey, suitable for technical analysis, some modifications of the contrast parameters were needed. Modifications made the images clearer (white) or darker (black) in order to render the reading of the voids and inclusions easier; in the dark/ black ones, porosities and cracks get very dark, while in the white ones, they get very clear. Internal traces visible in the X-ray image were classified according to the definitions set out in Berg (2008; 2009 and 2011) and Livingstone Smith and Viseyrias (2010).

\subsection{Late Bronze Age Pithoi found in Southern Italy}

In the Italian archaeological chronology, the LBA corresponds to two different phases, specifically the Recent Bronze Age (hereafter RBA, ca. 1325 to $1150 \mathrm{BC}$ ) and the Final Bronze Age (hereafter FBA, ca. 1150 to 990 BC) (Iacono et. al., 2021).

The production of large pithoi using levigated clay started in Southern Italy during the RBA. It commenced after contact with the Aegean area, leading to the introduction of the wheel device for pottery production; unknown until that time. In general terms, a clear difference is visible between the RBA pithoi and those of the FBA (Levi, 1999; and Schiappelli, 2003; 2015) (Figure 1). The known RBA specimens were probably barrel-shaped with no complete specimens being noted thus far, and they were decorated with wide plain bands. Sometimes these bands bear incised/ impressed patterns such as zig-zag or chevrons, as well as circles, criss-cross and herringbone. During the FBA, pithoi became larger than in the previous phase, being ovoidglobular in shape with a wide mouth, though the mouth was limited in comparison to the maximum diameter of other vessels. Small vertical handles were placed directly on the rim. The decoration consisted of horizontal grooves or a band with two, three or four ribs. Other specimens present ropes with impressed decorations. In the same way as in the RBA, decorations were placed on the main conjunction or join points of the vessels in order to reinforce them.

From a technological point of view, the presence of coils (or slabs) is clearly discernible in pithoi from cross-sections of fragments, as well as in wall thickenings in correspondence to the join point between two of them. Internal and external surfaces present fine- and medium-type rilling suggesting the 

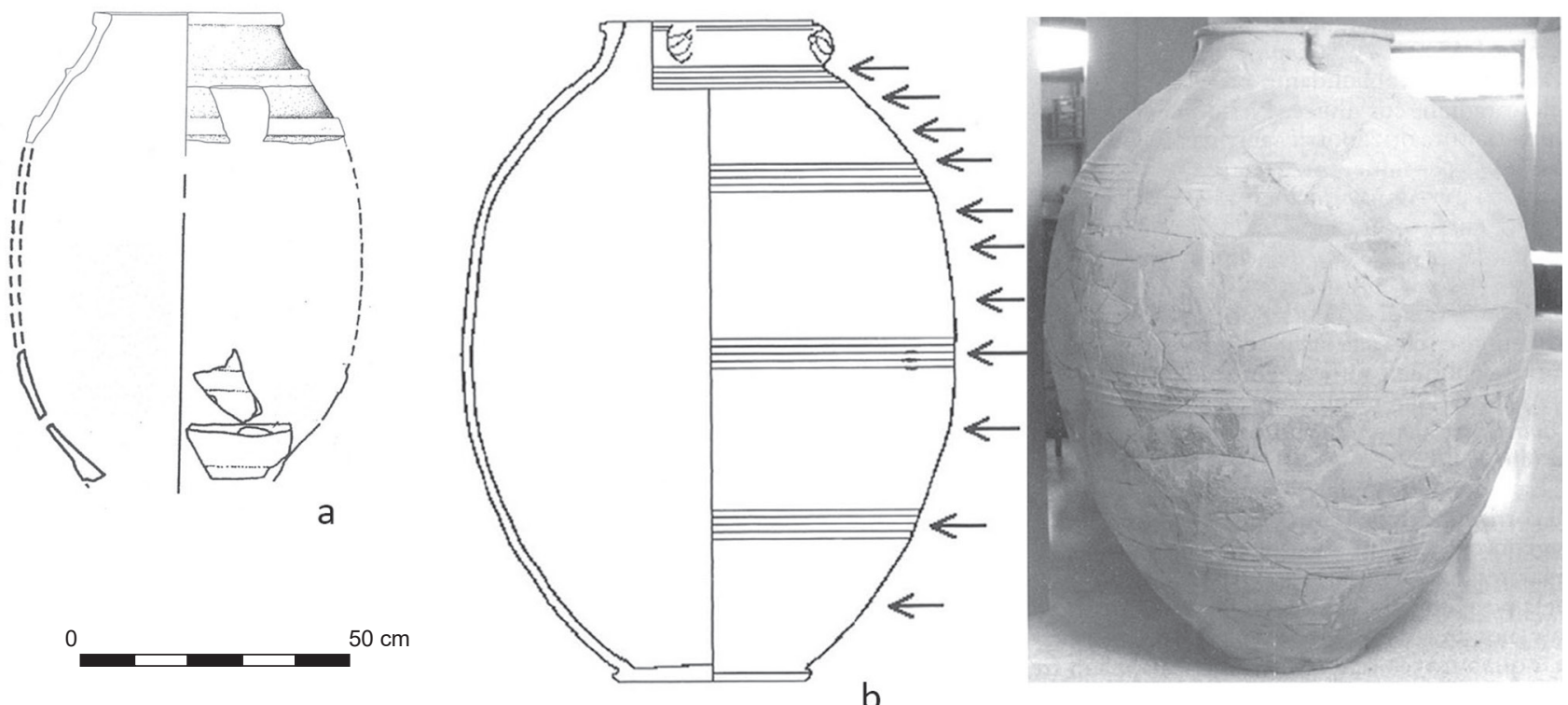

Figure 1. a) RBA pithos from Broglio di Trebisacce; b) Drawing and picture of a FBA pithos from Broglio di Trebisacce; the arrows indicate the joint point between coils (after Schiappelli, 2015 and Jones et. al., 2014, p.369 Figure 5.3b).

use of the wheel in their production. As the RBA and FBA differ typologically, as the vessels were made differently, RBA pithoi were probably made assembling large sections composed entirely of coils (Levi, 1999; Jones et. al., 2014; Schiappelli, 2015; Porta, 2019), conversely, as regards the FBA pithoi, each coil/slab was probably added to the previous one with the use of the wheel. The breakage mode reflects these differences in forming methods. In the RBA specimens, the main fractures run horizontally and are located in the join point between the sections where clay bands were usually positioned as reinforcements. By contrast, FBA pithoi breaks tend to be oblique or petal-shaped (for the definition of petalshaped, see Levi, 1999, p.175).

\subsection{The Experiments}

The overall aim of the experiments was to create an experimental collection of vessels to correlate with the LBA pithoi found in Southern Italy, Crete and Cyprus. Experimental vessels were used to explore the possibility that the LBA pithoi were produced using the wheel and not just simply refined on it. This was done thanks to the investigation of the relationship between the forming techniques, macroscopic traces on the surfaces, and traces detected using $\mathrm{X}$-rays. The two different experiments conducted responded to different necessities. Experiment No. 1 aimed to test the reasonableness of the hypothesis that during the FBA in Southern Italy, pithoi were made assembling large coils or slabs, each with the use of the wheel (Levi, 1999, p.203; Porta, 2019). In fact, Experiment No. 1 was based on the evidence of FBA pithoi unearthed in Broglio; the replica of Broglio pithos was realised with raw materials compatible with their ancient equivalent (Levi, 1999), and with the use of traditional tools and a non-motorised wheel type. In this sense, Experiment No. 1 could be classified as an actualistic
(Outram, 2008, p.2) or imitative experiment (Ascher, 1961; for a more general discussion, see Jeffra, 2015).

Experiment No. 2 responds to another requirement, being mainly used to verify the consistency of the wheelcoil methods noted in research studies with the production of large containers, and thus to produce the first referenced collection of macro and X-ray traces. For this reason, Experiment No. 2 did not consider any clay recipes, and it was performed operating with an electric wheel. This allowed the comparison of experimental items to pithoi produced in different Mediterranean areas, for example, Southern Italy, Crete and Cyprus, (Porta, 2019), and the fostering of comparative studies between them. In this way, this second experiment should be viewed as a general framework and a stepping stone for further context-orientated experiments, that is, actualistic and/or imitative.

\subsubsection{Experiment No. 1 -. Replica of the Broglio di Trebisacce Pithos $(B T)-F B A$}

The first experiment, Experiment No 1, is part of a broader set of experiments carried out over the last few years at the Archaeological Park in Broglio di Trebisacce (Calabria, Italy) by a research team led by Alessandro Vanzetti (Sapienza University of Rome). Such experiments were realised in collaboration with G. Pulitani, a professional potter and craftsman. Jones et. al. (2014, pp.393-402) provides a detailed report and an extensive commentary about these experiments. A further experimental session was carried out in 2015. It was specifically designed to address the reproduction of a FBA pithos based on the evidence recorded about the pithoi of Broglio di Trebisacce. The experimental pithos was produced using local clay extracted from the Trebisacce outcrops dating to the Pliocene Age; they were still exploited by local potters and brick manufacturers up 


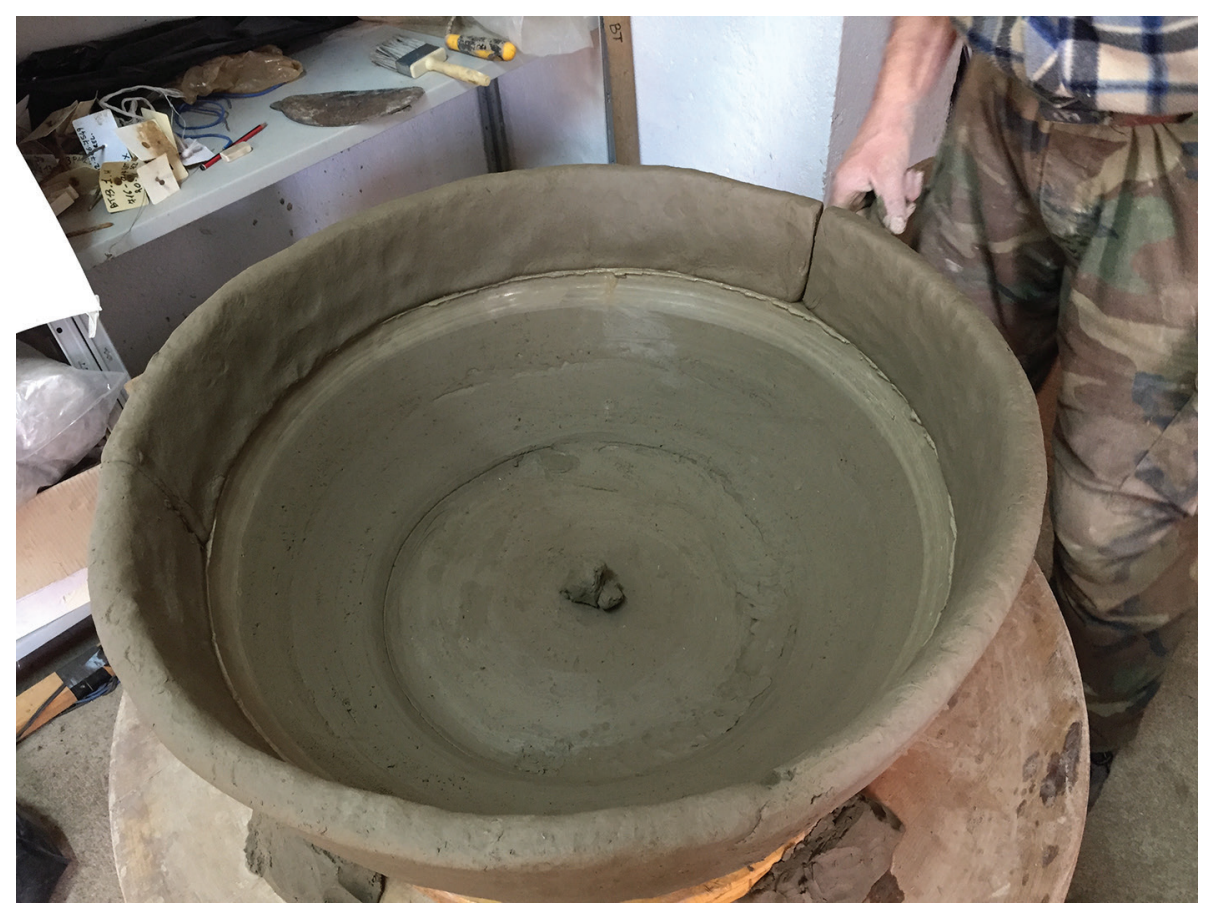

Figure 2. Experimental replica of a Broglio di Trebisacce FBA pithos. Band before cutting.

until the end of the $20^{\text {th }}$ century. This clay is very similar to that employed in the production of the local pottery unearthed in Broglio, as demonstrated by petrographic and chemical analyses (Levi, 1999, pp.125-126; Jones et. al., 2014). The clay was then tempered with crushed siltstone in accordance with Levi's results (1999, pp.145-154). The pithos replica was produced by progressively adding bands of clay (bands being manually flattened coils) that were joined to each other using a traditional wheel without a motor. The construction started with the base, whereby a clay mass was manually flattened, so becoming a clay disk of approximately $40 \mathrm{~cm}$ in diameter. The disk base was then refined with the use of a cloth and a metal paddle while turning the wheel at a very low speed. The first coil band was then positioned just on top of the base and carefully joined. The coil band was then worked with the wheel being turned by the assistant. The operation took around 9 minutes to be completed.

Thus, the main potter was assisted by a second operator who, during the entire experiment, manually turned the wheel (in an anti-clockwise rotation) reaching an average speed of $19.10 \mathrm{rpm}$ with a peak speed of around $29 \mathrm{rpm}$. Clay bands were shaped from larger clay coils and hand-flattened inside a rectangular wooden mould to produce bands of ca. $15 \mathrm{~cm}$ in width. The completion of the pithos took several days, with alternating drying phases and building phases, so allowing the clay to consolidate and thus preventing such a large vessel from cracking and breaking. In fact, a one-day break was necessary after each band was added and manipulated on the wheel. Starting from the second band level until the maximum expansion of the vessel, in order to reach the proper diameter, the potter preferred to produce and employ two half-circumference bands, joined together using horizontal motion. The addition of each new manufacturing level (a complete circumference band or two half-circumference bands) required about 9 minutes, mostly dedicated to joining operations, realised with vertical motion, with the lower band.

During the manufacturing process, the potter produced a band specifically dedicated to the present analysis (Figure 2). It was decided to cut the band to fit in the X-ray machine and to simulate single pithoi shards as found in archaeological contexts.

The band was placed on top of the previous one, following a regular and progressive assembling sequence. The potter joined the band, raised and thinned the wall of the body of the pithos using the wheel as previously done. Finally, the potter removed this band and went on with the manufacturing process.

Before the concluding stages (i.e., finishing operations and body smoothing) carried out by the potters, it was still possible to identify the main horizontal joins between the bands, as well as the vertical ones placed at each band termination (Figures 2-3). In the final stage, junctions and band terminations were completely erased and hidden by the careful smoothing done by the potter. The band used in this analysis was not subjected to the final treatments before its removal from the vessel.

\subsubsection{Experiment No. 2: Wheel-coiled Single Rings}

The second experiment, Experiment No. 2, realised in two distinct sessions in a potter's workshop in Rome with the collaboration of expert potter T. Calò, was instead aimed at testing the wheel-coiling methods as proposed by Roux and Courty (1998), and their consistency in the production of large containers. Due to budget and time constraints, rather than complete pithoi, the experiment consisted in replicating the four methods (mentioned further on) by assembling as many clay rings, each ring formed by way of amalgamating 
three to four coils together (Figures 5-8). The rings were meant to replicate, on a small-scale, the coil sequence used to form both the bodies and the necks, as identified through the macroscopic observation of the archaeological material.

In this experiment, clay recipes have not been included as a parameter of analysis and modern industrial clay was employed. The aim was rather to produce a more generalised typeset not considering the large variability of clay recipes, and their different degrees of coarseness, as attested to in the archaeological materials analysed. In order to build a standard experimental protocol (and to limit the variables to be considered), a modern electric wheel and kiln were used.

This second experiment was performed in two separate moments (Session A and Session B) in order to verify the variability of results obtainable from the work of a single potter by himself.

In Session B, performed a few months later, some corrections were also introduced, including the use of different colour clays (green-blue coloured clay), since their overlap made their join more visible.

Secondary operations like refining or decoration were not applied to the experimental rings in order not to obliterate primary forming traces on the surfaces. Before the turning operation, a wheel speed test was performed using each of its five gears (Table 1). In this way, having a speed reference, it was possible to see how much the speed decreased according to the force impressed by the potter during the work.

\section{Session A}

The first operation was the preparation of the clay, which was done by manually kneading $5 \mathrm{~kg}$ of modern industrial clay (the San Sepolcro type). This operation was necessary in order to make the consistency of the clay uniform as clay is usually drier on its outside when compared to its inside. Once the clay was ready, part of it was used to create the wheel-thrown base of the vessel for the experimentation of the wheel-coiling methods. The base was entirely wheelthrown, and it was not intended to be a replica of the forming methods of the LBA pithoi. When ready, the base measured $18 \mathrm{~cm}$ in height and $30 \mathrm{~cm}$ in diameter. The thickness of the base was $2 \mathrm{~cm}$, while the thickness at the mid-height of its body wall and its upper section was $1.5 \mathrm{~cm}$.

The potter then further worked the mixture, adding $0.50 \mathrm{~g}$ of manganese oxide powder and $200 \mathrm{~g}$ of quartz sand to the clay. Manganese oxide was added as a tracer for the $\mathrm{X}$-rays, while the quartz sand was used as a temper. The use of quartz sand rather than crushed quartz is due to the requirement to produce more uniform final vessels, avoiding the risk of tempering clay with quartz inclusions of different granulometry.

Since the clay was very wet, it was allowed to rest to reach the optimum consistency in order to continue the work. The experimental session continued three days later. As a first operation, the clay was re- kneaded. The coils were formed using a clay extruder and so were not made by hand as in Experiment No. 1. The diameter of the section of each coil was about $2 \mathrm{~cm}$. The dimensions of the diameters were smaller than that of the pithoi from Broglio (Levi, 1999, pp.202-203) as, for technical reasons, it was impossible to use coils of greater dimension. The preparation of the 20 coils took one hour.

Each ring was produced by joining together four coils at a time and subsequently detaching them from the wheelthrown base that mimicked the base of the pithos. These

Table 1. Electric wheel's gears.

\begin{tabular}{cc}
\hline Gear & Speed (rpm) \\
\hline 1 & 49.53 \\
2 & 76.07 \\
3 & 95.54 \\
4 & 132.69 \\
5 & 168.08 \\
\hline
\end{tabular}

rings were cut in half before drying to produce two half-ring bands (Figures 5-8). This operation was aimed at obtaining fresh cross-sections in order to enhance the visibility of the coils and the orientation of the temper. Moreover, these bands had a shape that is more suitable for X-ray analysis. $\mathrm{X}$-raying single bands instead of rings we avoided the risk of overlapping the traces of the two sides, obtaining a better comprehension of the voids/tempers arrangement and orientation.

After a drying time of three days, the bands were fired in an electric muffle kiln for 30 hours at a temperature of $960^{\circ} \mathrm{C}$.

Method 1: The ring was realised using four coils with a cross-section diameter of $2 \mathrm{~cm}$. The potter used the second gear speed. Working time: 9 minutes (average time per coil: 2.25 minutes).

Method 2: The ring was realised using four coils with a cross-section diameter of $2 \mathrm{~cm}$. The potter used the second gear speed. Working time: 13.04 minutes (average time per coil: 3.26 minutes).

Method 3: The ring was realised using three coils with a cross-section diameter of $2 \mathrm{~cm}$. Mr. Calò underlined that, during the throwing operation, the coils were still not joined together. The potter used the first and second gear speeds. Working time: 7 minutes (average time per coil: 2.33 minutes).

Method 4: The ring was realised using three coils with a cross-section diameter of $2 \mathrm{~cm}$. Each coil was thrown on the wheel. After the throwing operation, in order to prepare the coil for the positioning of a new one, its upper section was slightly smoothed. To facilitate the joining operation, Mr. Calò made a light nail impression. The potter used the second gear speed. Working time: 13 minutes (average time per coil: 4.33 minutes).

\section{Session B}

The first operation was the preparation of the clay, which was done by mixing up $3 \mathrm{~kg}$ of modern industrial clay (the San Sepolcro type). Less clay was needed in this case because the rings were made directly on the wheel without 


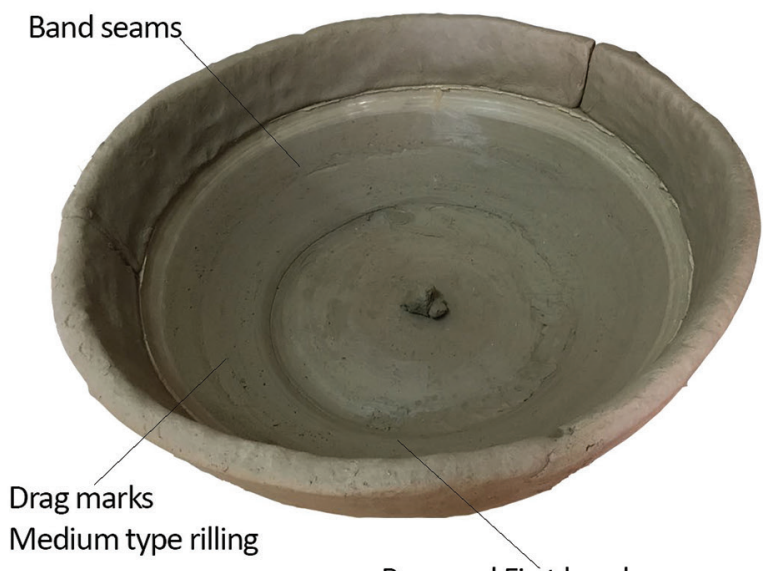

Base and First band seam

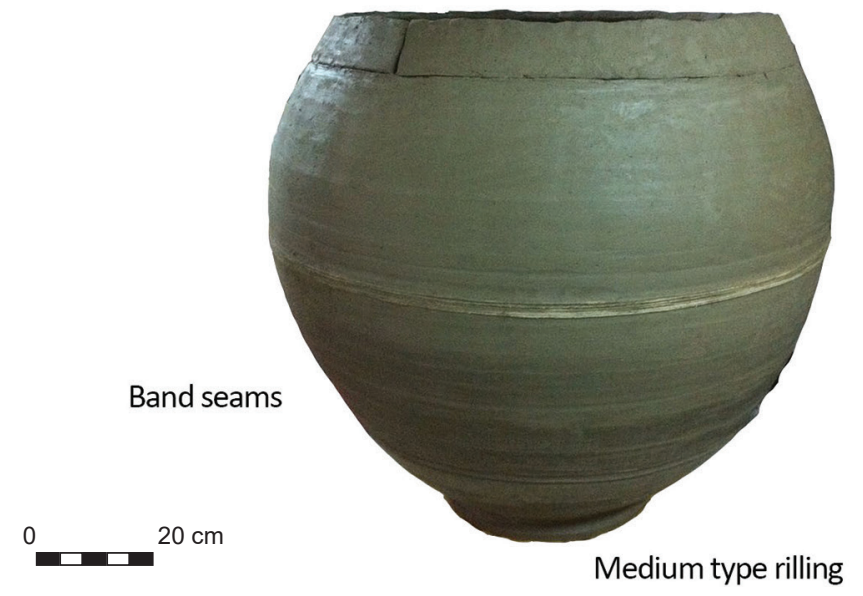

Figure 3. Macro traces on experimental pithos.

a base. A quantity of $0.50 \mathrm{~g}$ of manganese oxide powder and $200 \mathrm{~g}$ of quartz sand were added to the clay. Half of the clay prepared was then kneaded together with cobalt oxide powder in order to obtain a green/blue colour. The coils were formed using a clay extruder; the diameter of the coils was $2 \mathrm{~cm}$. The preparation of the 20 coils took one hour. Each ring was formed by placing four coils, one by one, directly on the wheel head according to the guidance provided by scholars for each method, and then subsequently detached from the wheel. Finally, rings were cut in half before the drying phase in order to produce two half-ring bands. After a drying time of three days, the bands were fired in an electric muffle kiln for 30 hours at a temperature of $960^{\circ} \mathrm{C}$.

Method 1: The ring was realised using four coils with a cross-section diameter of $2 \mathrm{~cm}$; grey clay coils were
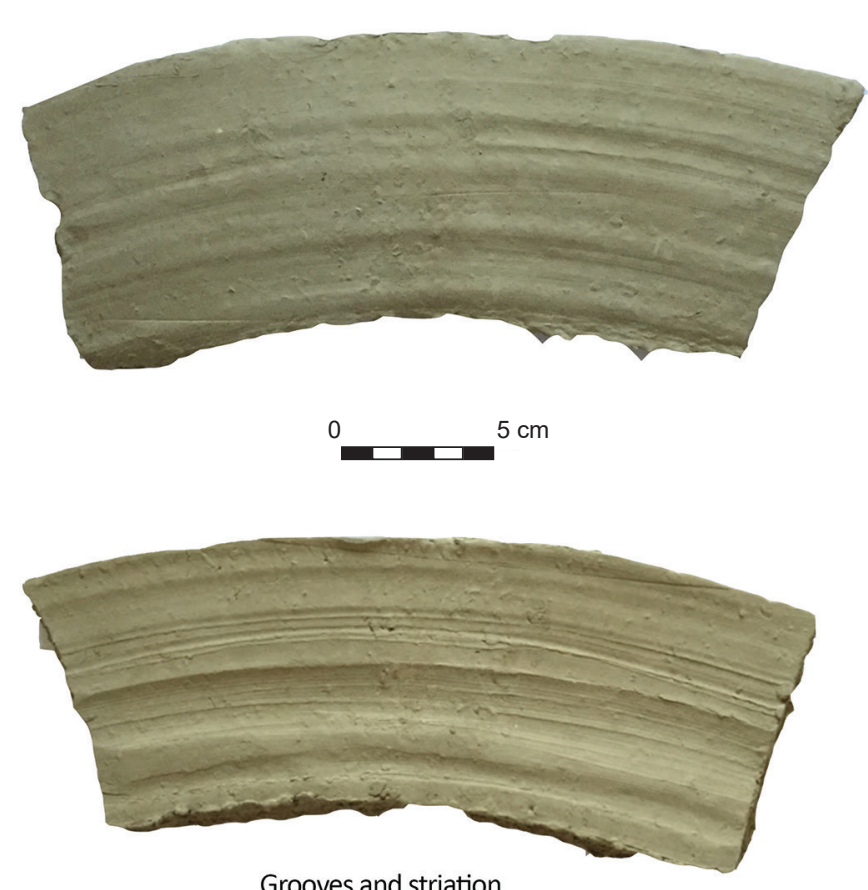

External Surface

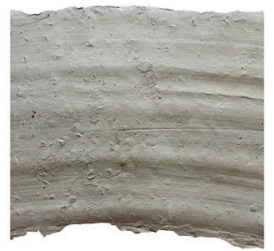

Fine to Medium Rilling

Internal Surface
Figure 4. Experiment n. 1: BT Pulitani's band with main macrotraces on surfaces. 
Method 4: The ring was realised using four coils with a cross-section diameter of $2 \mathrm{~cm}$; grey clay coils were alternated with green ones with the first coil always being grey. In this case, in order to facilitate the throwing of the coil, Mr. Calò used an extra coil on the wheel on which, afterwards, he fixed the first coil of the band. Each coil was thrown on the wheel. After the throwing operation, to prepare the coil for the positioning of a new one, its upper surface was slightly smoothed. To facilitate the joining operation, Mr. Calò made a light nail impression. The potter used the second gear speed. Working time: 26 minutes (average time for coil: 5.2 minutes).

\section{Results}

\subsection{Observation of the Macro Traces on the External and Internal Surfaces}

\subsubsection{Experiment No. 1: Replica of the Broglio di Trebisacce Pithos - FBA}

As shown in Figure 3, the internal surface of the pithos base presents medium rilling and drag marks. The join points between the different sections are still visible. In the uppermost band (the experimental cut-off band), there are also clearly recognisable finger impressions formed due to

\section{METHOD 1_Session A}
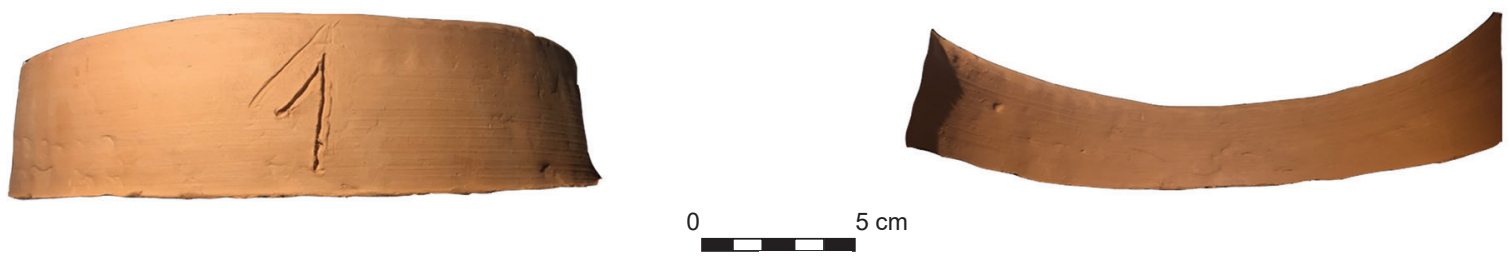

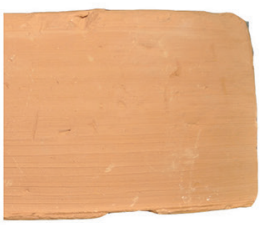

Fine Rilling

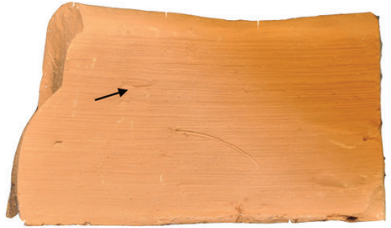

Drag Marks

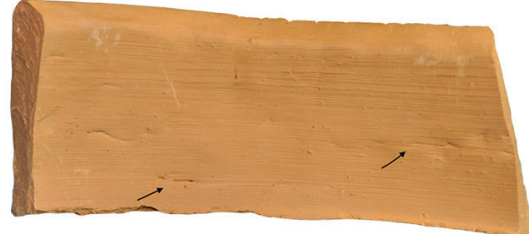

Incompletely joined coils

\section{METHOD 1_Session B}
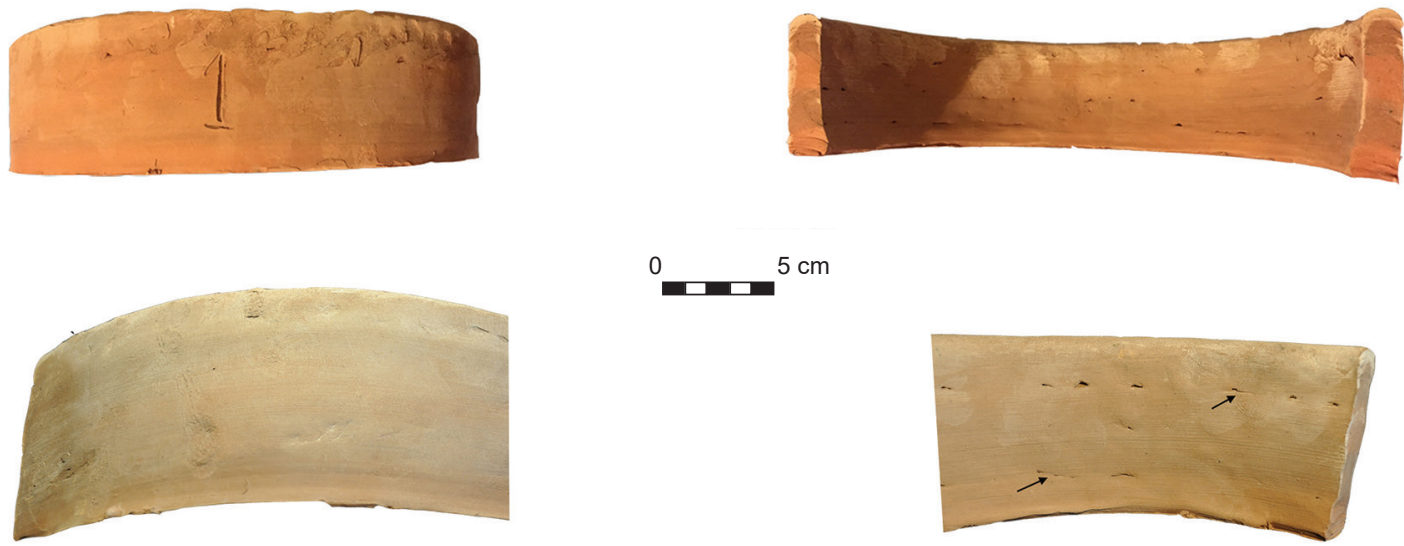

Fine Rilling

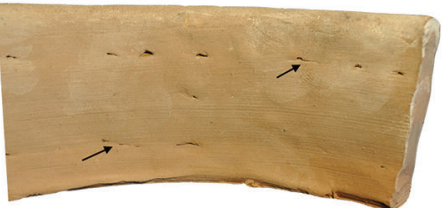

Incompletely joined coils

Figure 5. Experiment n. 2: Method 1 band with main macrotraces on surfaces. 


\section{METHOD 2_Session A}

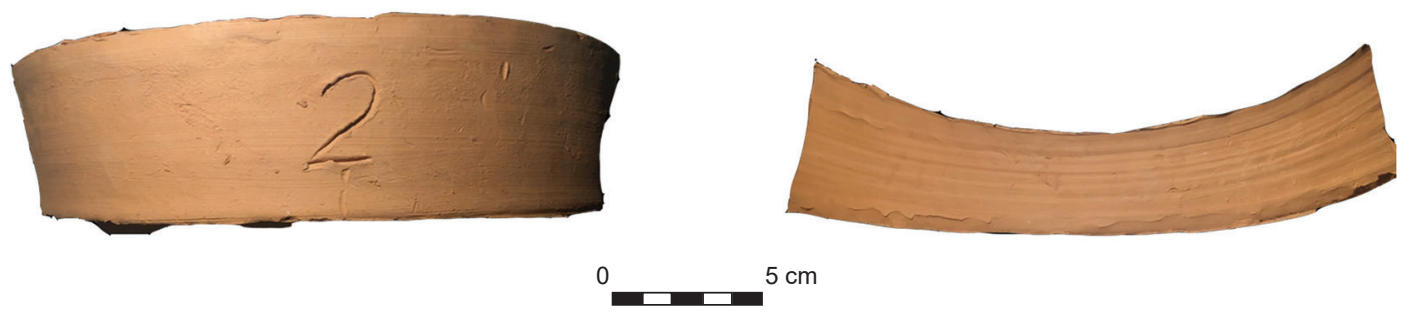

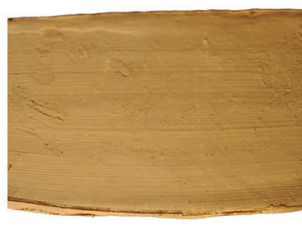

Fine Rilling

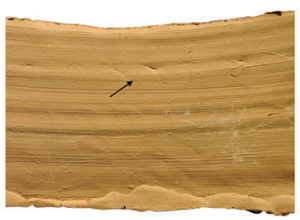

Incompletely joined coils

Medium Rilling

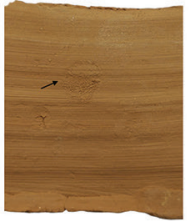

Finger Impression

\section{METHOD 2_Session B}
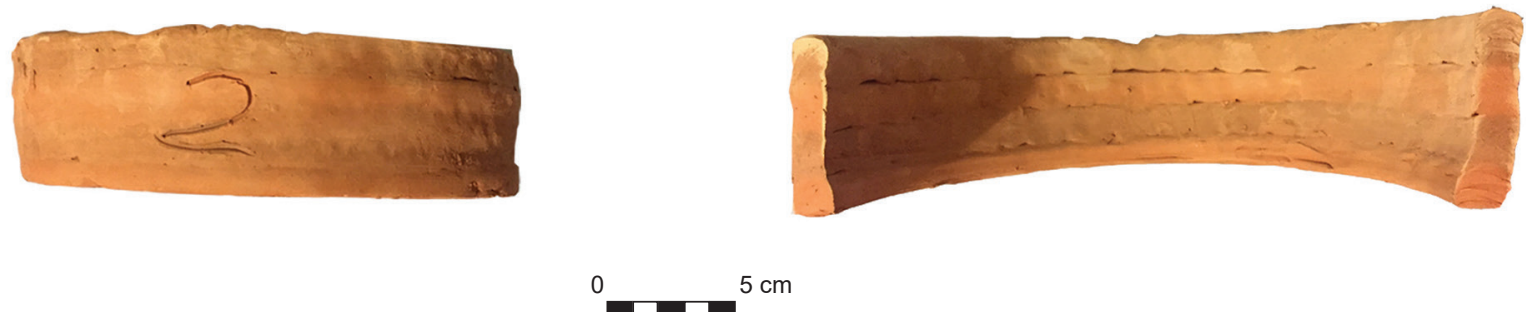

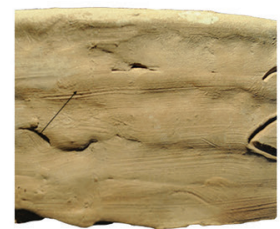

Incompletely joined coils

Rilling not parallel to coils

Thickness Discontinuities

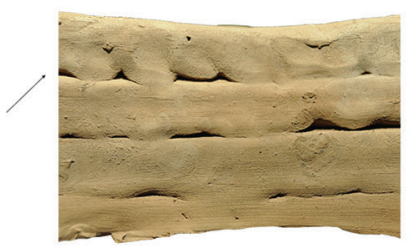

Incompletely joined coils

Figure 6. Experiment n. 2: Method 2 band with main macrotraces on surfaces.

the pressure exercised by the potter in shaping the wall. On the external surface, parallel medium-type rilling is visible beside the main join points between sections; these were completely obliterated later by the smoothing and finishing operations.

On its external surface, the experimental band presents fine to medium rilling and drag marks. Grooves and concentric striations were clearly visible to the naked eye on the internal surface of the band. (Figure 4).

\subsubsection{Experiment No. 2: Wheel-coiled Single Rings (Figures 5 to 8)}

Bands produced with Method 1 are mainly characterised by the fine and regular rilling on the internal and external surfaces. The Method 1 Session A band is very regular with a low recurrence of incompletely-joined coils. Method 1 Session B presents, on the contrary, a higher degree of incompletely-joined coils, especially visible on the internal wall. The band realised with Method 2 Session A presents 


\section{METHOD 3_Session A}
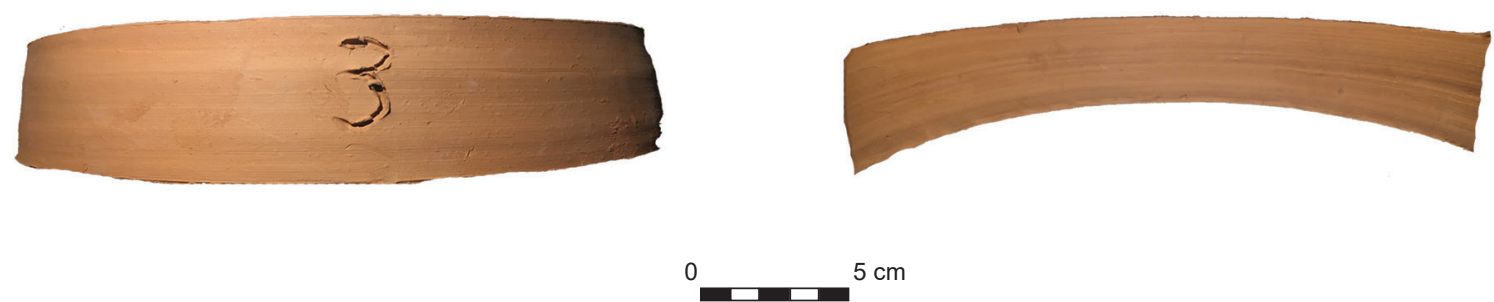

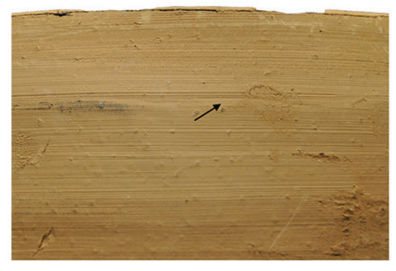

Coils seam

Fine Rilling

\section{METHOD 3_Session B}
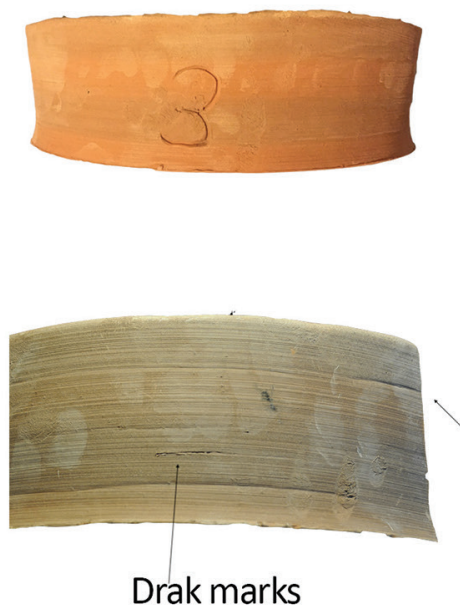

Coils seam

\section{Fine Rilling}

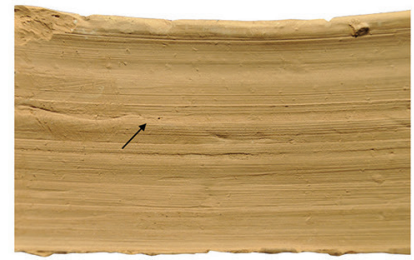

Coils seam

Fine to Medium Rilling
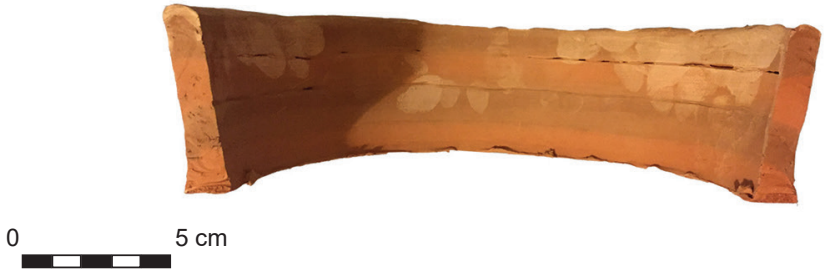

Figure 7. Experiment n. 2: Method 3 band with main macrotraces on surfaces.

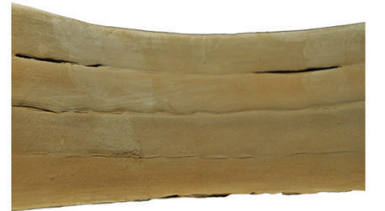

Incompletely joined coils

Fine Rilling fine rilling on the external surface, whilst having a more irregular medium type rilling on its inner wall. As in the previous case, the band realised during Session B presents incompletely-joined coils. Thickness discontinuities are also visible, and sometimes rilling is running not parallel to coils.

The Method 3 Session A band is globally regular presenting fine rilling on the external surface and fine to medium - less regular - rilling on the internal one. Coils are perfectly joined but a coils seam is still visible on the band.
Method 3 Session B's band is globally regular presenting fine rilling on the external and internal surface. However, incompletely joined coils are still visible on the internal wall. The external surface is also characterised by the presence of a drag mark and a coils seam is visible.

On the external wall of the Method 4 Session A band one can notice incompletely joined coils and a coils seam. In this case, whilst the external surface presents fine and regular rilling, the internal one is mainly characterised by a more pronounced medium-type rilling. 

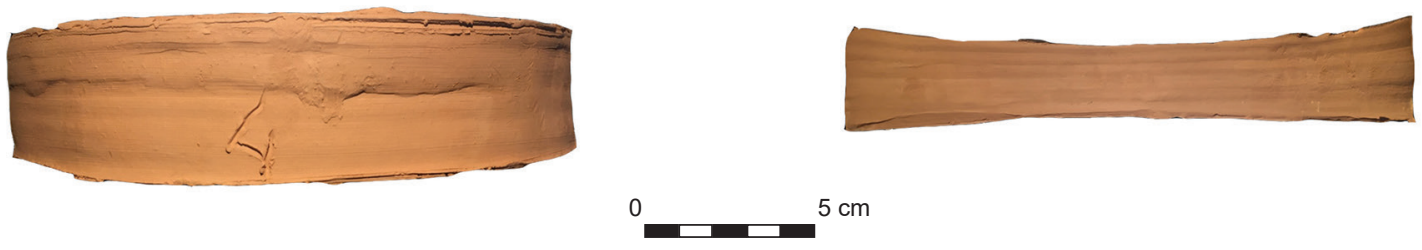

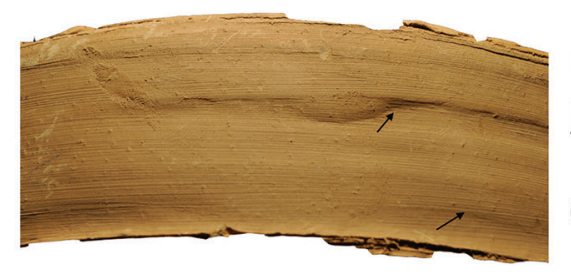

Fine Rilling

\section{Incompletely joined coils \\ Coils seam}

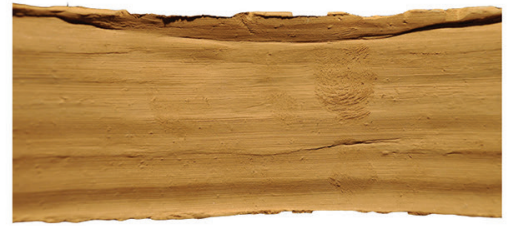

Medium Rilling

\section{METHOD 4_Session B}

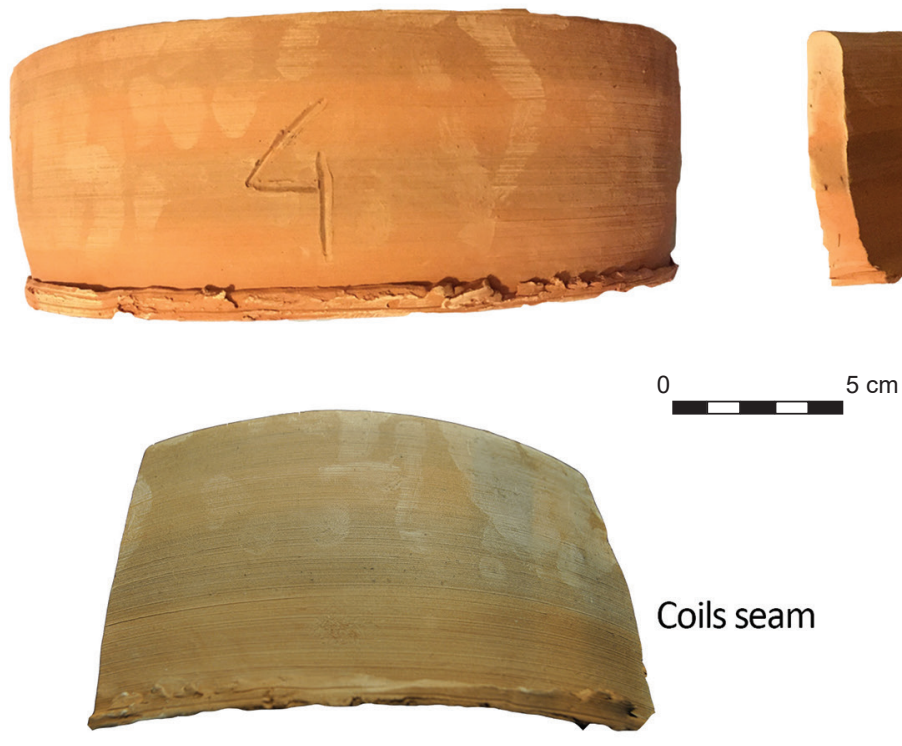

Fine Rilling

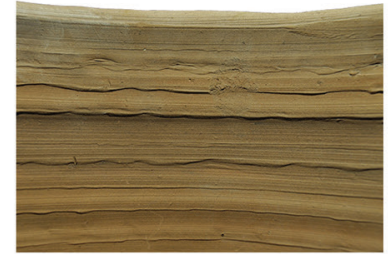

Medium Rilling

Figure 8. Experiment n. 2: Method 4 band with main macrotraces on surfaces.

The Session B band presents fine and regular rilling on the external surface and, as in the previous case, medium type rilling on the internal one.

\subsection{Observation of the Internal Modification of the Clay using X-Ray Technology}

\subsubsection{Experiment No. 1: Replica of the Broglio di Trebisacce Pithos, $F B A$}

Most of the inner surface traces (voids and inclusions) maintained a consistent horizontal orientation. Only a few diagonally-orientated voids and inclusions are visible.
However, the general pattern is chaotic overall and not aligned along either a horizontal or vertical axis (Figure 9).

\subsubsection{Experiment No. 2: Wheel-coiled Single Rings (Figures 10 to 13)}

In most of the experimental items analysed coils' seams are clearly visible (Figures 10-13). In all the bands temper and voids take a preferential horizontal alignment. Exceptions are bands produced with Methods 4, and Method 3-session B in which some elements clearly take an oblique inclination (Figures 12-13). The presence of coils is further corroborated by thickening in correspondence with the coils seam. 
Figure 9. Experiment n. 1: BT Pulitani's band X-ray image with main micro features (above the original X-ray and below the image with diagnostic traces)

\section{BT Experimental Band}

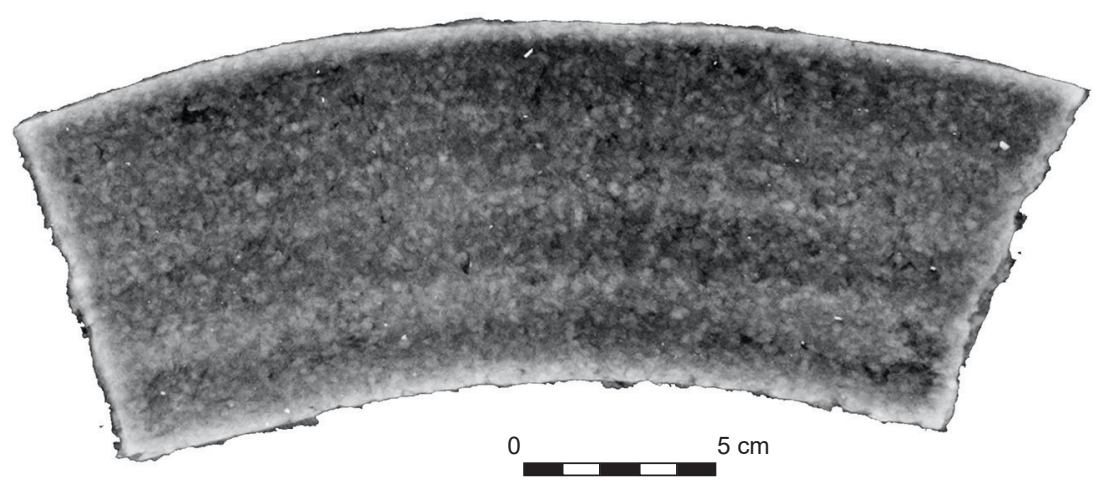

Horizontally oriented inclusions and voids

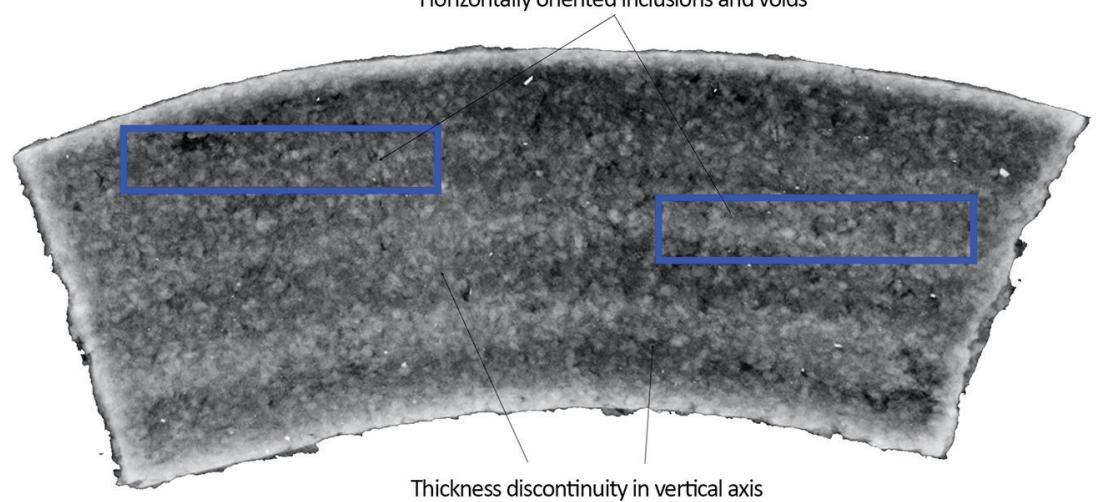

Thickness discontinuity in vertical axis
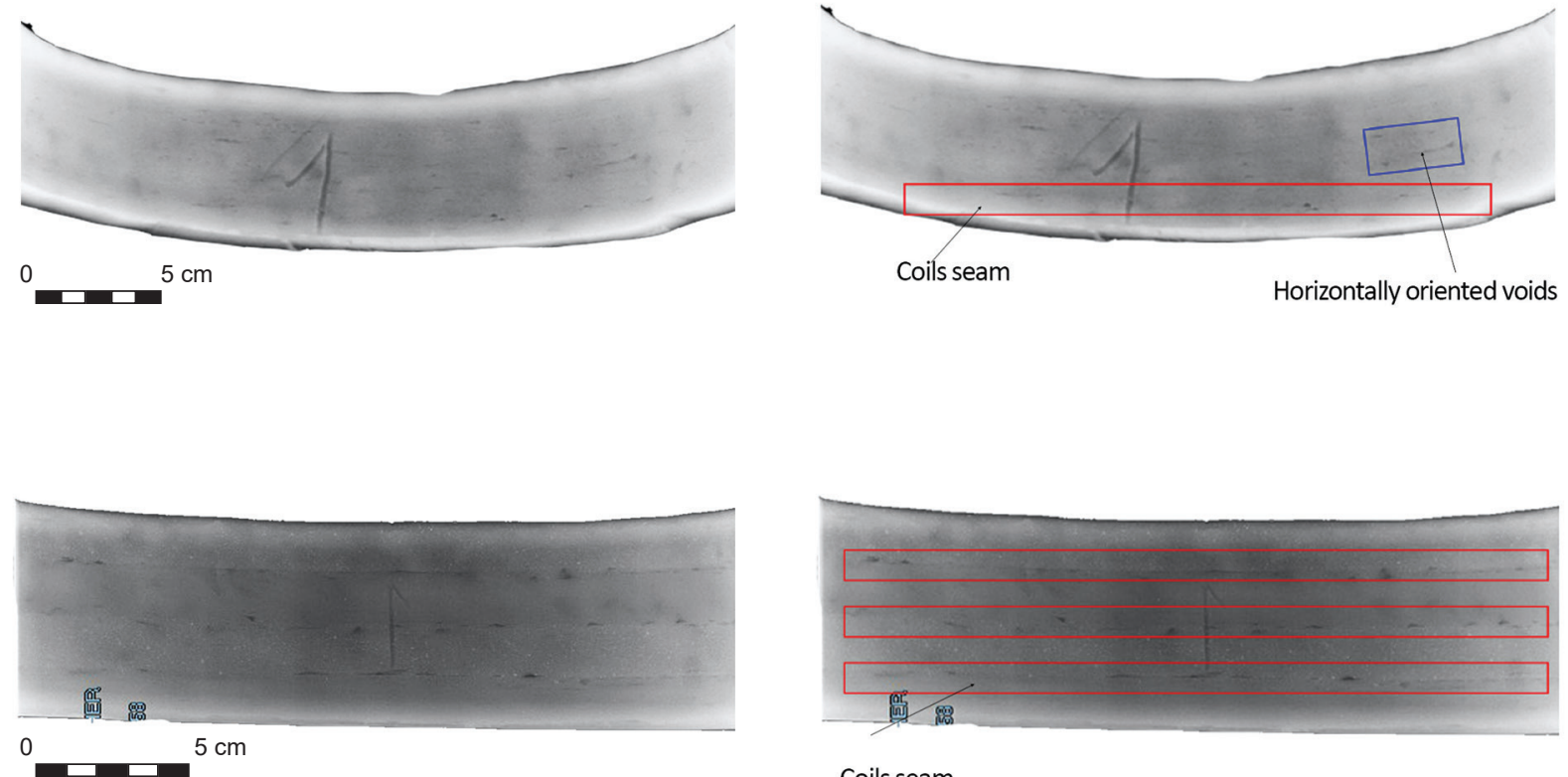

Coils seam

Figure 10. Experiment n. 2: Method 1 band X-ray image with main micro features (on the left side the original X-ray and on the right side the images with diagnostic traces).

\section{Discussion}

Although only at an initial stage, the results of these two experiments have proved to be very useful in the investigation of prehistoric pithoi, as they present the possibility that these large containers were actually produced using the wheel. The macro traces identified on the surfaces of some of the ancient vessels - for example, rilling, drag marks, and thickness discontinuities along the vertical axis, and their X-ray profile (horizontal fractures in the join points, horizontally- 

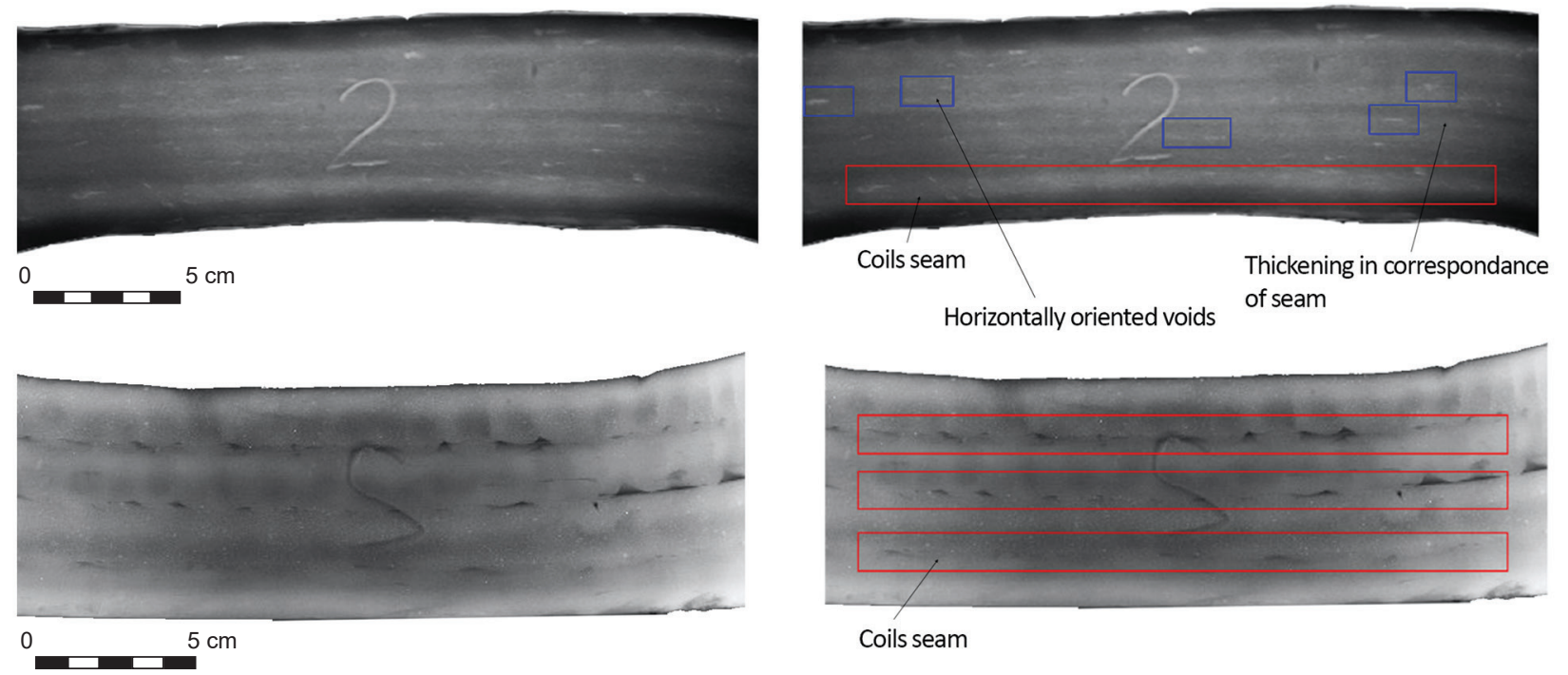

\section{Coils seam}

Figure 11. Experiment n. 2: Method 2 band X-ray image with main micro features (on the left side the original X-ray and on the right side the images with diagnostic traces).
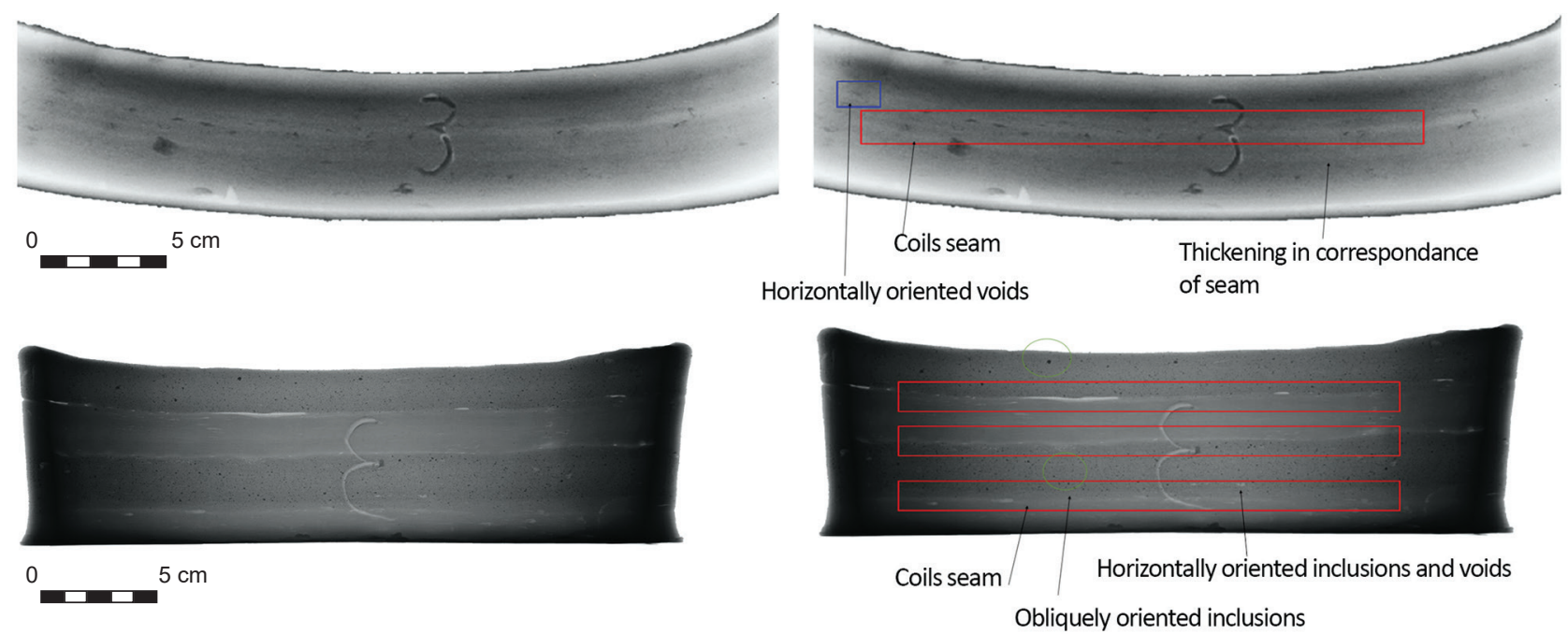

Figure 12. Experiment n. 2: Method 3 band X-ray image with main micro features (on the left side the original X-ray and on the right side the images with diagnostic traces).
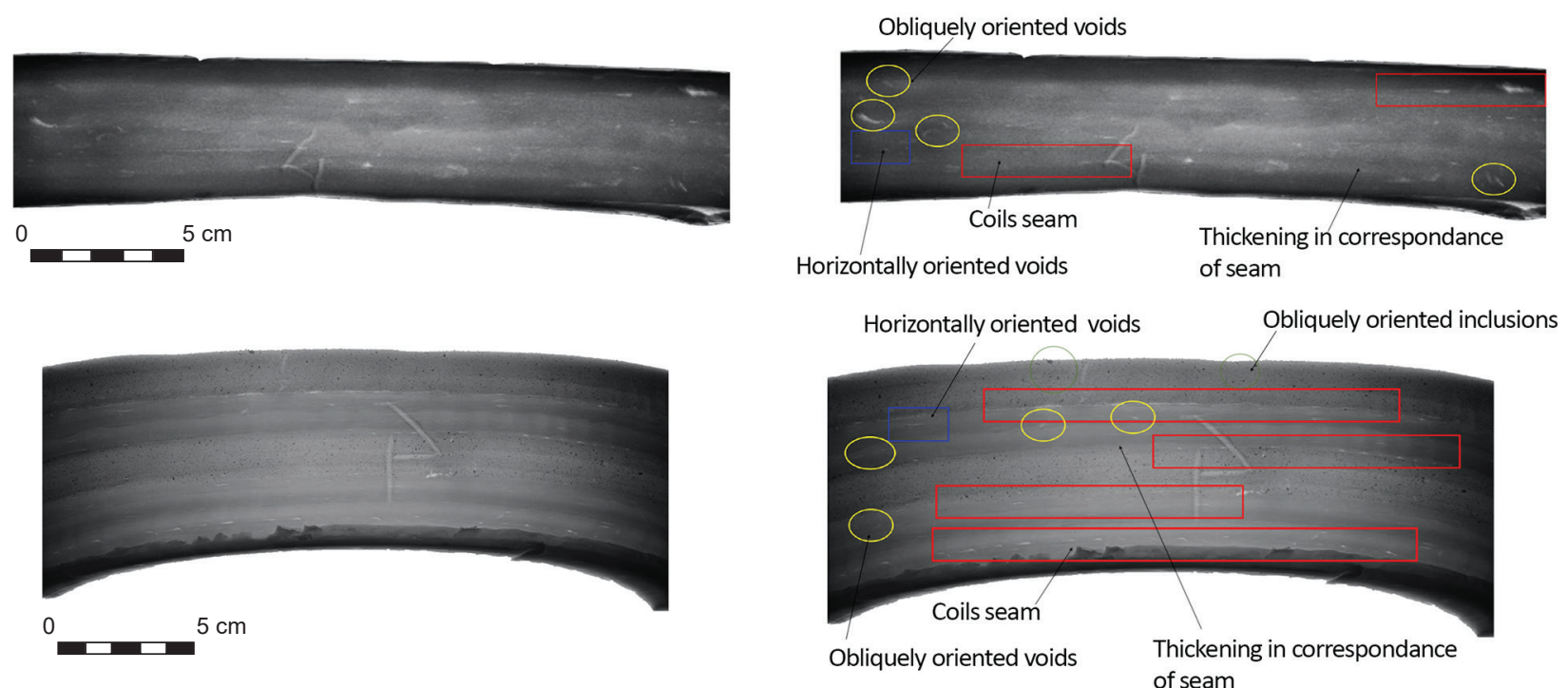

Figure 13. Experiment n. 2: Method 4 band X-ray image with main micro features (on the left side the original X-ray and on the right side the images with diagnostic traces) 
Table 2. Summary of all the surface and X-ray features identified for each method replicated in Rome by T. Caló alongside those visible in the Experiment No. 1 band.

\begin{tabular}{ll}
\hline Exp. No. 1 Band & $\begin{array}{l}\text { External surface presents fine type rilling and drag marks. Grooves and concentric striations on the internal surface } \\
\text { of the band. The RKE energy produces a slight modification of the band, in the X-ray image tempers and voids } \\
\text { maintain a preferential chaotic alignment. }\end{array}$ \\
\hline Method 1 & $\begin{array}{l}\text { Joins between coils remain still visible in the final product. The surfaces present a fine rilling. The RKE energy } \\
\text { produces a slight modification of the band, while in the X-ray image tempers and voids maintain a preferential } \\
\text { horizontal alignment. }\end{array}$ \\
\hline Method 2 & $\begin{array}{l}\text { Joins between coils remain still visible in the final product. The surfaces present rilling, sometimes not parallel to } \\
\text { the coils. Differences in wall thickness in the horizontal axis. The RKE energy produces a slight modification of } \\
\text { the band, while in the X-ray image tempers and voids maintain a preferential horizontal alignment. }\end{array}$ \\
\hline Method 3 & $\begin{array}{l}\text { Joins between coils remain still visible in the final product. The external surfaces present fine rilling. The } \\
\text { RKE energy produces a slight modification of the band, while in the X-ray image tempers and voids maintain } \\
\text { a preferential horizontal alignment with only few elements obliquely oriented. }\end{array}$ \\
\hline Method 4 & $\begin{array}{l}\text { Joins between coils remain still visible in the final product. Formation of medium type rilling on the internal } \\
\text { surface and grooves. The RKE energy modified the wall and led to rhythmic changing in wall thickness on } \\
\text { correspondence to the coils. In X-ray image some elements take an oblique inclination. }\end{array}$ \\
\hline
\end{tabular}

orientated voids besides oblique ones) - generally match with those of the experimental materials (Porta, 2019 with earlier references). Further studies, including context-related experiments (see above), are needed in order to associate ancient pithoi with more specific wheel-coiling methods and to address similarities and differences among pithoi found in different Mediterranean contexts in a diachronic perspective.

Tables 2 and 3 summarise all the surface and X-ray features identified for each method replicated in Rome by T. Caló, alongside those visible in the Experiment No. 1 band, which could be classified as a hybrid between slab construction and (wheel) coiling. In this case, the advantage would be the use of elements that do not have to be completely modified/ formed on the wheel by the potter using Rotational Kinetic Energy (RKE). Macro traces on the surface of the vessel result from the pressure exerted by the potter to enlarge its diameter, as well as the slight smoothing of its surface using a cloth during the lifting and thinning operations on the wheel. Taking the X-rays into consideration, most of the inner traces, voids and inclusions, maintained a preferential horizontal orientation while the general pattern is chaotic. This is probably due to the manual flattening of the original coils made by G. Pulitani to produce one band before putting it on the wheel; this only marginally modified the internal structure of the clay. New experiments should assess the

Table 3. Macrotraces visible in the experimental items analysed.

\begin{tabular}{|c|c|c|c|c|c|c|c|c|c|c|c|c|c|c|c|c|c|c|c|}
\hline & & 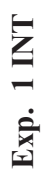 & 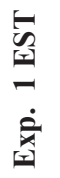 & $\begin{array}{l}\text { 叓 } \\
\Xi\end{array}$ & $\begin{array}{l}5 \\
6 \\
5 \\
\square\end{array}$ & $\begin{array}{l}\underline{E} \\
\stackrel{\varphi}{Z}\end{array}$ & 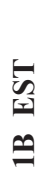 & $\begin{array}{l}\text { 艺 } \\
\text { 㫕 }\end{array}$ & $\begin{array}{l}\text { 봉 } \\
\text { a } \\
\text { 崩 }\end{array}$ & 乬 & 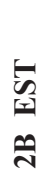 & 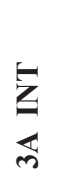 & 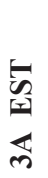 & $\frac{\tilde{Z}}{\tilde{m}}$ & $\begin{array}{l}\text { ज्ञ } \\
\text { ले } \\
\text { लै }\end{array}$ & $\begin{array}{l}\text { Z } \\
\text { Z }\end{array}$ & 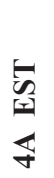 & $\begin{array}{l}\underline{\xi} \\
\stackrel{\varphi}{\sigma}\end{array}$ & 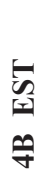 \\
\hline \multirow{2}{*}{$\begin{array}{l}\text { Costruction-related } \\
\text { traces }\end{array}$} & Coil Seam & & & & & & $\mathrm{X}$ & & & & & $\mathrm{X}$ & $\mathrm{X}$ & & $\mathrm{X}$ & & $\mathrm{X}$ & & $\mathrm{X}$ \\
\hline & $\begin{array}{l}\text { Incompletely joined } \\
\text { coils }\end{array}$ & & & $\mathrm{X}$ & $\mathrm{X}$ & $\mathrm{X}$ & $\mathrm{X}$ & $X$ & $X$ & $X$ & $\mathrm{X}$ & & & $\mathrm{X}$ & & & $\mathrm{X}$ & & \\
\hline $\begin{array}{l}\text { Costruction/shaping } \\
\text { related traces }\end{array}$ & $\begin{array}{l}\text { Finger impression } \\
\text { due to pression }\end{array}$ & & & & & & & & & $X$ & $\mathrm{X}$ & & & & & & & & \\
\hline \multirow{2}{*}{ Thinning } & $\begin{array}{l}\text { Thickness } \\
\text { discontinuities in } \\
\text { vertical axis }\end{array}$ & $\mathrm{X}$ & & & & & & & & & & & & & & $\mathrm{X}$ & & $\mathrm{X}$ & \\
\hline & $\begin{array}{l}\text { Thickness } \\
\text { discontinuities in } \\
\text { horizontal axis }\end{array}$ & & & & & & & & & $X$ & & & & & & & & & \\
\hline \multirow{5}{*}{$\begin{array}{l}\text { Rotational-related } \\
\text { traces }\end{array}$} & Fine Rilling & & $\mathrm{X}$ & $\mathrm{X}$ & $\mathrm{X}$ & $\mathrm{X}$ & $\mathrm{X}$ & & $\mathrm{X}$ & & & & $\mathrm{X}$ & $\mathrm{X}$ & $\mathrm{X}$ & & $X$ & & $\mathrm{X}$ \\
\hline & Medium Rilling & & & & & & & $X$ & & & & $\mathrm{X}$ & & & & $\mathrm{X}$ & & $\mathrm{X}$ & \\
\hline & $\begin{array}{l}\text { Grooves/concetric } \\
\text { striation }\end{array}$ & $\mathrm{X}$ & & & & & & & & & \multirow{3}{*}{$\mathrm{X}$} & & & & & & & & \\
\hline & $\begin{array}{l}\text { Rilling not parallel } \\
\text { to coils }\end{array}$ & & & & & & & & & & & & & & & & & & \\
\hline & Drag marks & & $\mathrm{X}$ & $\mathrm{X}$ & & & & & & & & & & & $\mathrm{X}$ & & & & \\
\hline
\end{tabular}


suitability of this method for the interpretation of Bronze Age pithoi, and compare the final appearance of fragments and vessels produced with the bands, as opposed to those made with (non-flattened) coils.

Sessions A and B, carried out by the same potter, but at two separate points in time, resulted in the production of vessels that are extremely different from each other. They enabled the verification of the presence of macro traces on the surface, as well as confirming that the quality of the final product is strongly conditioned by the work performed by the potter. This could indicate that some differences, visible in the ancient samples, do not depend on different technological operations, but are rather the result of internal variation inside the same chaînes opératoires (Roux, 2017).

Moreover, despite the potter's experience and proficiency in the use of the wheel over a period of 15 years, differences in the final vessels in terms of macro traces could also be attributed to the fact that the experimentation involved a series of wheel-coiling methods partially unknown to him (reproduced only twice), which would have required a longer period of learning and adaptation. This unfamiliarity with the technique used could indeed have influenced the final results and the formation of the traces, as was recently demonstrated by the experimental work conducted by Gandon and Roux (2019) while in Jahangirabad, Uttar Pradesh, Northern India. According to the scholars in question, producing on the wheel unfamiliar shapes led to a lower level of reproducibility of the behaviour of the ancient potters, and consequently to a lower degree of standardisation in the final vessels (Gandon and Roux, 2019, p.237). Moreover, Gandon and Roux underlined how the cost of the motor skill adaptation to new shapes (or methods in this case) is inversely related to the proficiency of the potter. In general, this adaptation is easier for highly expert potters already engaged in the production of a wide assemblage of pots in terms of shape and size, while it is more demanding for potters only specialised in the production of a few small-sized shapes. In the case here, preliminary training and a wider production sample might have led to more uniform vessels thanks to the improvement in the proficiency of the potters as regards these specific methods and shapes. Moreover, a greater production would have enabled the measurement of the internal differences in the final vessels, and to evaluate the degree of metric standardisation of the experimental samples.

Despite these differences, each of the four wheel-coiling methods produced containers that present rilling on their surfaces resulting from rotation on the wheel. The presence of coils is underlined by wall thickening in correspondence to the join point between two coils (also visible in X-ray images). Coil seams are often still visible in the final vessel both in frontal view and in cross-section. In some cases, coils remain incompletely joined. As expected, the use of clays of different colour facilitated the identification of coils, their seam and the effects of RKE energy upon them. In general, the bands produced with Methods 3 and 4 were more deformed from the use of the wheel than the others, as their internal surfaces present more marked rilling, especially in conjunction with the coil seam. This also appears to be confirmed by X-ray, especially in the bands of Method 4, where it is possible to observe obliquely-orientated voids and temper. Thus, X-rays confirm the progressive and increasing deformation caused by the wheel from Method 1 up to Method 4 .

Considering the relation between macro traces and X-ray micro features (Figures 9-13), the most important result is the identification of coil seams in the X-ray images in the form of elongated voids aligned along a horizontal axis. In the case of incompletely-joined coils, voids became actual horizontal micro fractures running along the horizontal axis. The presence of coils is also indicated by thickening (darker in the black X-ray images) in correspondence with the coil seam. In the Experiment No 1 band, thickness discontinuities in the vertical axis are due to the thinning operation operated with RKE energy and not to the presence of coil seams, since the band is a single flattened coil.

The traces identified in these experimental vessels sustained and validated the interpretation of the traces visible in the X-ray images of the Broglio di Trebisacce pithoi as wheel-coiled productions. X-ray images of the Broglio pithoi show traces of the joins between coils, sometimes made by fingerprints or "toothing" incisions, as well as horizontallyorientated voids and inclusions, besides obliquely-orientated ones (Levi, 1999; Jones et. al., 2014; Porta, 2019).

As stated, the necessity to increase the use of X-ray technology on experimental and ethnographic samples is fundamental in understanding and interpreting the traces. The correct identification of the coil seam, the degree of deformation, and the related traces caused by the wheel in each wheel-coiled method need to be better interpreted on experimental vessels, thus preventing the misinterpretation of the ancient ones.

In general, the second experiment, Session B, showed a higher average working time than the first session (Figure 14), that is, working on rings realised directly on the wheel head is more complex than working on a real growing pot (Experiment No. 2, Session A). However, it is still not clear how working directly on the wheel head affected the potter's work, that is, the reproducibility (sensu Gandon and Roux, 2019) of the behaviour of the potters, and hence the quality of the finished vessels. However, the higher occurrence of incompletely-joined coils in Session B could be related to this and not to random variations.

Method 4 was, in both experimental sessions, the method that had the longest average time. Thus, despite being the method that best exploits the potential of the wheel, it is the most time-consuming one. This period of time only takes into consideration the time spent to position and work on each coil, and not their preparation - as they were made before starting the wheel operations. It is worthwhile noting that slight differences in time also relate to the need to add more clay to coils to complete the diameter of each ring. This happened randomly and not in direct relation with a specific method. It depended solely on the fact that the coils made in advance were not of the same length and sometimes were not 
Figure 14. Average working time for each method. $\mathrm{X}$ axis reports the methods; $\mathrm{Y}$ axis the working time $(\mathrm{min})$.

\section{Average Time fo each coil}

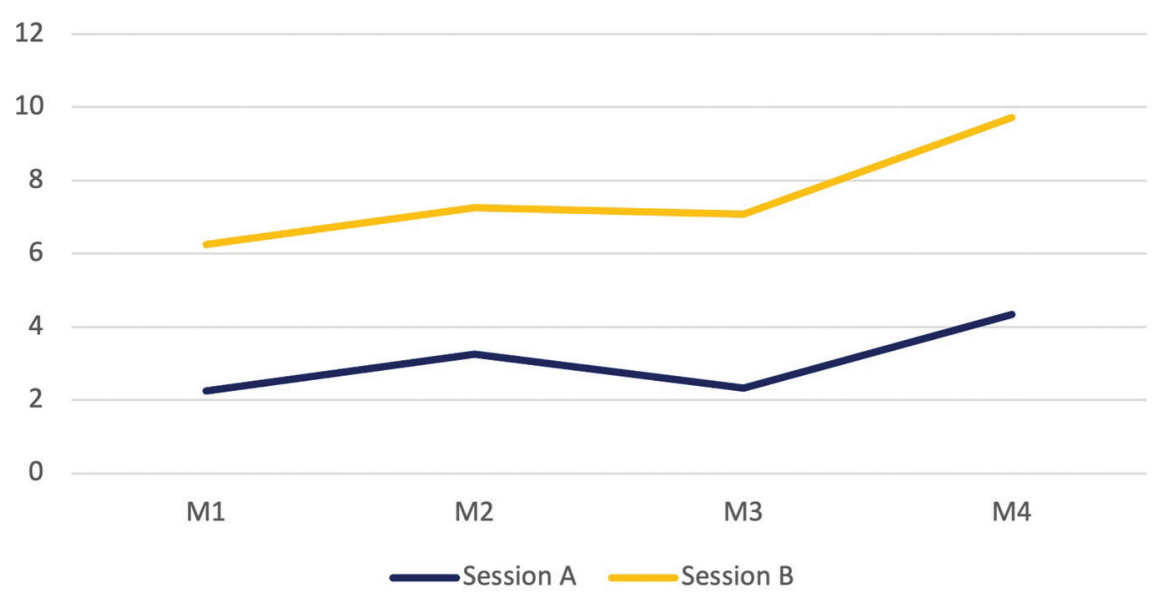

long enough to complete the diameter of the ring. However, the coil-terminations were completely erased and so are not visible in the final product.

As expected in Experiment No. 1, the use of a traditional non-motorised wheel increased the production time, doubling or tripling the number of minutes taken to work on each band. New experimentations will also allow to verify the different degree of deformation of coils caused by the use of different types of wheels (traditional $v$ electric) and thus to test the value of experimental items produced with modern electric wheels in the interpretation of ancient vessels.

The experiments also underlined that the speed required is not an absolute value even in wheel-coiling methods, but varies according to the type of activities performed, as well as to the part and the typology of the vessels. The potter did also intend to change the gear speed between one coil and another. He generally worked at a low speed - first and second gears - and sometimes increased the gear speed for a short time in order to join the coils or to refine the surface. Conversely, in the manufacture of the wheel-thrown base, he used the top gear and worked at a very high speed, especially during the centring operation.

\section{Conclusion}

The data presented here are the preliminary results of an investigation that combines experimental archaeology, visual inspection and X-ray technology in the analysis of vessels such as pithoi that are sometimes under-estimated in technological studies.

This contribution aims to underline the importance of the detailed analysis of pithoi in the broader study of pottery technology. Indeed, the analysis of pithoi offer the possibility of obtaining a more complete picture of the pottery production within a community, enabling the verification of similarities and differences with other pottery classes, and so the co-existence of different circuits of potters in the intergroup community.

The construction of large vessels, which require technological assistance due to their size, is very different to the construction of smaller vessels. In this sense, comparing and referring to technological traces from experimental collections replicating small vessels (or to traces on small ancient vessels) can be risky. Several issues need to be considered in the analysis of pithoi: for example, different parts of the same vessels, that is, the rim, neck, body and base, can be made in different ways and therefore the mode of construction identified for one part may not be necessarily valid for another. Moreover, a detailed analysis of each part of the body of the vessel could offer the possibility to verify the existence of different traditions and different circuits of potters. The similar forming method used to create the Broglio and Roca Vecchia (Le, Apulia) pithoi, but with differentlyshaped bases, raise the possibility of the existence of different potting traditions being more or less simultaneously active in Southern Italy (Guglielmino, 1999; Levi, 1999).

Even though the reproduction of partial bands, and not complete vessels, could create different types of traces or the total lack thereof, that is, marks related to the lower part of the vessels, including distortions or component construction traces, and the later attachment of the neck, this preliminary research presents some interesting results. It also makes clear the necessity for further testing of wheel-coiling methods using an experimental protocol specifically dedicated to large vessels. The experimental replica of one pithos from the FBA, conducted at Broglio, enabled the evaluation of a further technical option, namely the progressive addition of bands instead of coils with the aid of the wheel.

Given the positive results of this trial experiment of the wheel-coiling methods (Experiment No. 2), new experiments are now required to test these methods in a more actualistic context, with raw materials similar to the those used to make the archaeological vessels along with the use of a non-electric wheel and kilns conforming to the available evidence dating to the LBA. Future replicas should also include secondary 
operations to further improve the interpretation of the traces found on ancient vessels and to be better able to differentiate wheel-made from wheel-finished vessels.

\section{Acknowledgements}

This paper is the outcome of experimental sessions carried out in past years thank to the collaboration of several people and under the aegis of Sapienza - University of Rome. I wish to express my profound gratitude to G. Pulitani, A. Sotgia, G. Calò, and M. Di Micco for helping me in the realization of the experimental items. I also would like to thank F. Odoguardi for the X-ray analyses, and for his suggestions in the interpretation of the X-ray images. I am very grateful to D. Sciocco, M. Revello Lami, I. Caricola, D. Moscone and F. Di Biase for the time that they have dedicated to debate this text with me. Finally, I am also grateful to the two anonymous reviewers who showed interest in this work and made helpful comments to improve the manuscript. Obviously, all remaining mistakes are mine.

\section{References}

ASCHER, R., 1961. Experimental Archeology 1. American Anthropologist, 63, 793-816. DOI: 10.1525/aa.1961.63.4.02a00070.

BEVAN, A., 2014. Mediterranean containerization. Current Anthropology, 55(4), 387-418.

BERG, I., 2008. Looking through pots: Recent advances in ceramics X-radiography. Journal of Archaeological Science, 35(5), 1177-1188.

BERG, I., 2009. X-radiography of Knossian Bronze Age vessels: Assessing our knowledge of primary formation techniques. Annual of the British School at Athens, 104, 137-174.

BERG, I., 2011. Exploring the chaîne opératoire of ceramics through X-radiography. In: S. Scarcella, ed. Archaeological Ceramics: A Review of Current Research. Oxford: BAR International Series, 2193, pp. 1-7.

BLITZER, H., 1990. KOPONEÏKA: storage-jar production and trade in the traditional Aegean. Hesperia, The Journal of the American School of Classical Studies at Athens, 59, 675-711.

CHOLEVA, M., 2012. The First Wheelmade Pottery at Lerna: WheelThrown or Wheel-Fashioned? Hesperia, The Journal of the American School of Classical Studies at Athens, 81(3), 343-381.

COLES, J., 1979. Experimental Archaeology. London: Academic Press.

COURTY, M-A. and Roux, V., 1995. Identification of wheel throwing on the basis of ceramic surface features and microfabrics. Journal of Archaeological Science, 22(1), 17-50.

CHRISTAKIS, K.S., 2005. Cretan Bronze Age Pithoi: Traditions and Trends in the Production and Consumption of Storage Containers in Bronze Age Crete. Prehistory Monographs, 18, Philadelphia: INSTAP Academic Press.

CHRISTAKIS, K.S., 2008. The Politics of Storage: Storage and Sociopolitical Complexity in Neopalatial Crete. Prehistory Monographs, 25, Philadelphia: INSTAP Academic Press.

DESOGUS, P., LEVI, S.T. and VANZETTI, A., 1995. An experiment to foster the study of pottery wheel-throwing speed. In: P. Vincenzini, ed. The ceramics cultural heritage. Firenze: Academic of Ceramics, Faenza, Techna - Monographs in Materials and Society, 2, pp. 317-324.

GANDON, E. and ROUX, V., 2019. Cost of motor skill adaptation to new craft traits: Experiments with expert potters facing unfamiliar vessel shapes and wheels. Journal of Anthropological Archaeology, 53, 229-239.

GIANNOPOULOU, M., 2010. Pithoi. Technology and history of storage vessels through the ages. Oxford: Archeopress, BAR International Series, 2140 .
GIANNOPOULOU, D. and DEMESTICHA, S., 2008. Ta metavezantina apothekeetika ayyeia ton mastichochorion tes Chioe. In: E Ye-Metra zoes kai themioeryias. Praktika epistemonikes senanteses. $19^{\text {th }}-21^{\text {st }}$ March 2004. Athens: Moeseio Ellenikes Laïkes Technes, 187-194.

GUGLIELMINO, R., 1999. I dolii cordonati di roca Vecchi (Le) e il problema della loro derivazione egea. In: V. La Rosa, D. Palermo, L. Vagnetti, eds. Epi ponton plazomenoi. Simposio italiano di studi egei dedicato a luigi Bernabò Brea e Giovanni Pugliese Carratelli. Roma. $18^{\text {th }}-20^{\text {th }}$ February 1998. Roma, pp. 475-486.

HAMPE, R. and WINTER, A., 1962. Bei Töpfern und Töpferinnen in Kreta, Messenien und Zypern. Mainz: Romisch-Germanisches Zentralmuseum.

IACONO, F., BORGNA, E., CATTAN, M., CAVAZZUTI, C., DAWSON, H., GALANAKIS, Y., GORI, M., IAIA, C., IALONGO, N., LACHENAL, T., LORRIO, A., MICÓ, R., MOLlOY, B., NAFPliOTI, A., PECHEQUILICHINI, K., RIHUETE HERRADA, C., RISCH, R., 2021. Establishing the Middle Sea: The Late Bronze Age of Mediterranean Europe (1700-900 BC). Journal of Archaeological Research, 2021. DOI: 10.1007/s10814-021-09165-1.

JEFFRA, C.D., 2015. Experimental approaches to archaeological ceramics: unifying disparate methodologies with the chaîne opératoire. Archaeological and Anthropological Sciences, 7, 141-149.

JEFFRA, C.D., 2011. The archaeological study of innovation: An experimental approach to the pottery wheel in Bronze Age Crete and Cyprus. Unpublished thesis (PhD), Department of Archaeology, University of Exeter.

JONES, R.E., LEVI, S.T., VAGNETTI, L. and BETTELLI, M., 2014. ItaloMycenaean pottery: the archaeological and archaeometric dimension. Roma: Incunabola Greca.

KESWANI, S.P., 2017. Pithoi from Pano Mantilaris and Paliotaverna. In: S. Hadjisavvas, ed. Alassa. Excavations at the Late Bronze Age Sites of Pano Mantilaris and Paliotaverna 1984-2000. Lefkosia, Cyprus: Department of Antiquities, pp. 629-641.

KESWANI, S.P., 1989. The Pithoi and other plain vessels. In: Vasilokos Valley Project III: Kalavassos - Ayio Dhimitrios II: Ceramics, Objects, Tombs, Specialist studies. Göteborg: Studies in Mediterranean Archaeology, 71(3), pp. 12-21.

KESWANI, S.P., 1989. The Pithoi and other plain vessels. In: A. South, P.A. Russell, and P. Schuster Keswani: Vasilokos Valley Project III: Kalavassos - Ayio Dhimitrios II: Ceramics, Objects, Tombs, Specialist studies. Göteborg: Studies in Mediterranean Archaeology, 71(3), pp. 12-21.

KIBAROĞLU, M., THUMM-DOĞRAYAN, D., 2013. Trojan pithoi: A petrographic approach to provenance of Bronze Age storage vessels from Troy. Applied Clay Science, 82, 44-52.

LANERI, N., 2009. Biografia di un Vaso. Paestum: Pandemos.

LEVI, S.T., 1999. Produzione e circolazione della ceramica nella Sibaritide protostorica. Vol. I. Impasto e dolii. Firenze: All'Insegna del Giglio.

LIVINGSTONE SMITH, A., and VISEYRIAS, A., 2010. Shaping Kabambian pottery: identification and definition of technical features. The Open Anthropology Journal, 2010, 124-141.

MANZANILlA, L. and ROTHMAN, M., 2016. Storage in Ancient Complex Societies. Administration, Organization, and Control. New York, London: Routledge.

MARGOMENOU, D. and ROUMPOU, M., 2011. Storage Technologies as Embedded Social Practices: Studying Pithos Storage in Prehistoric Northern Greece. In: A. Brysbaert, ed. Tracing Social Networks Through Studying Technologies: A Diachronical Perspective from the Aegean. New York: Routledge, pp. 126-142.

O'SULLIVAN, A., POWERS, M., MURPHY, J., INWOOD, N., GILHOOLY, B., KELLY, N., MALONE, W., MULROONEY, J., CORRIGAN, C., L'ESTRANGE, M., BURKE, A., KAZURO, M., MCDERMOTT, C., WARREN, G., O'NEILL, B., HEFFERNAN, M., and SWEENEY, M., 2014. Experimental Archaeology: making; understanding; story-telling. In: B. Kelly B., N. Roycroft, and M. Stanley, eds. Fragments of Lives Past: archaeological objects from Irish road schemes. Archaeology and the National Roads Authority Monograph Series, 11, pp. 115-126.

OUTRAM, A.K., 2008. Introduction to experimental archaeology. World Archaeology, 40, 1-6.

PILIDES, D., 2000. Pithoi of the Late Bronze Age in Cyprus: Types from the Major Sites of the Period. Nicosia: Department of antiquities, Cyprus. PORTA, F., 2019. Value and territories. Pithoi, Storerooms and 
Redistribution across The Eastern Mediterranean, Aegean and Italy during the Bronze Age. Unpublished thesis (PhD), La SapienzaUniversity of Rome and Ghent University.

PRESTON DAY, L., GESELL, G.C., DIERCKX, H.M.C., FLINT-HAMILTON, K., GLOWACKI, K.T., KLEIN, N.L., REESE, D., SNYDER, L.M., HODGINS, G., 2016. Kavousi IIC: The Late Minoan IIIC Settlement at Vronda: Specialist Reports and Analyses. Philadelphia: Prehistory Monographs, 52.

PRIVITERA, S., 2010. I granai del re. L'immagazzinamento centralizzato delle derrate a Creta tra il XV e il XIII sec. a.C., Padova: Il Poligrafo.

REYNOLDS, P.J., 1999. The nature of experiment in archaeology. In: A.F. Harding, ed., Experiment and design: archaeological studies in honour of John Coles. Oxford: Oxbow, pp. 156-162.

ROUX, V., 2019. Ceramics and Society: A Technological Approach to Archaeological Assemblages. Nanterre: Springer.

ROUX, V. 2017. Ceramic manufacture: the chaîne opératoire approach. In: A. Hunt, ed. The Oxford Handbook of Archaeological Ceramic Analysis. Oxford: Oxford University Press, pp. 101-113.

ROUX, V. and COURTY, M.-A., 1998. Identification of wheel-fashioning methods: technological analysis of $4^{\text {th }}-3^{\text {rd }}$ millennium $\mathrm{BC}$ oriental ceramics. Journal of Archaeological Science, 25(8), 747-763.
SHIAPPELLI, A., 2015. Along the routes of the pithoi in the Late Bronze Age. In: A. Babbi, ed. The Mediterranean Mirror. Cultural Contacts in the Mediterranean Sea between 1200 and 750 BC, Mainz: Verlag des Römisch-Germanischen Zentralmuseums, pp. 231-243.

SHUSTER KESWANI, P., 2009. Exploring regional variation in Late Cypriot II-III pithoi, Perspectives from Alassa and Kalavasos. In: I. Hein, ed. The Formation of Cyprus in the $2^{\text {nd }}$ millennium B.C. Wien: Studies in Regionalism during the Middle and Late Bronze Ages, pp. 107-126.

THÉR, R., 2016. Identification of pottery-forming techniques using quantitative analysis of the orientation of inclusions and voids in thin sections. Archaeometry, 58(2), 222-238.

VOYATZOGLOU, M., 1974. The Jar Makers of Thrapsano in Crete. Expedition, 16(2), 18-24.

VANKILDE, H. 2016. Catalogue and introduction to the catalogue of pithoi. In: E. Hallager, and B.P. Halllager, eds. The Greek-Swedish Excavations at the Agia Aikaterini Square Kastelli, Khania 1970-1987. Stockholm, pp. 341-373.

VECA, C., 2015. Innovation and tradition in technology of large storage jars of the Sicilian Middle Bronze Age. In: Proceedings of the XV SOMA (Catania University, $3^{r d}-4^{\text {th }}$ March 2011). BAR International Series, 2695(I), Oxford: Archaeopress, pp. 239-248. 
